\title{
HUBUNGAN GAMBARAN FOTO WATERS DAN GEJALA KLINIK PADA PENDERITA DENGAN DUGAAN SINUSITIS MAKSILARIS DI RSUP PROF DR. R. D. KANDOU MANADO PERIODE 1 OKTOBER 2012-30 SEPTEMBER 2013
}

\author{
${ }^{1}$ Ni Kadek Ayu Isyana Wardani \\ ${ }^{2}$ Ramli Hadji Ali \\ ${ }^{2}$ Elvie Loho
}

\author{
${ }^{1}$ Kandidat Sarjana Fakultas Kedokteran Universitas Sam Ratulangi Manado \\ ${ }^{2}$ Bagian Radiologi Fakultas Kedokteran Universitas Sam Ratulangi Manado \\ Email: ayu_wardani41@yahoo.com
}

\begin{abstract}
Sinusitis is an inflamation of Mukosa Paranasal Sinuses in which is determined as the cause for the distraction of human's health that often be suffered by human being in the entire of the world. The well-known sinusitis found is maxillary sinusitis and etmoidalis sinusitis . There are some clinic examination can be done to suspect the existence of maxillary sinus such as anamnesis, physical inspection and radiologi inspection. An inspection through Photo Waters is usually being done to evaluate the infection of paranasal sinus, giving an appropriate evaluation moreover to the minor disease on kovum sinus. The main purpose of this research is to find out the relationship between the description of photo waters and the clinic symptom on the patients with the suspicious of maxillary sinusitis in RSUP prof. Dr.R.D. Kandou manado period of time 1 october 2013-30 september 2013. This research concerns to the analytic correlatic retrospective. The data is collected from sheet of paper in which shows the symptom clinic of maxillary sinusitis and the result of the description of the Photo Waters. Based on the test of correlation Kendal'tau_b the significant value of $(p)=0,272>0,05$ and the correlation coefficient $(r)=0,150$ in which shows that there is a weak positive relationship with the low test value between the description of Photo Waters and clinic symptom on the patients suspicious for maxillary sinusitis.
\end{abstract}

Keywords: Maxillary sinusitis, Clinical symptoms, Photo Waters

\begin{abstract}
Abstrak: Sinusitis adalah inflamasi mukosa sinus paranasal yang dianggap sebagai salah satu penyebab gangguan kesehatan tersering diseluruh dunia. Sinusitis yang paling sering di temukan ialah sinusitis maksilaris dan sinusitis etmoidalis. Ada berbagai pemeriksaan klinik yang dapat dilakukan untuk mencurigai adanya sinusitis maksilaris seperti anamnesis, pemeriksaan fisik dan pemeriksaan radiologi. Pemeriksaan Foto Waters adalah pemeriksaan yang paling sering digunakan untuk mengevaluasi infeksi sinus paranasal, memberikan evaluasi yang tepat meskipun pada kelainan ringan pada kavum sinus. Tujuan penelitian ini adalah mengetahui hubungan gambaran Foto Waters dan gejala klinik pada penderita dengan dugaan sinusitis maksilaris di RSUP Prof DR. R. D. Kandou Manado Periode 1 Oktober 2012-30 September 2013. Penelitian ini adalah penelitian analitik korelatik retrospektif. Data berupa lembaran gejala klinik sinusitis maksilaris dan hasil gambaran Foto Waters. Berdasarkan uji korelasi Kendall'tau_b nilai signifikan $(p)=0,272>0,05$ dan koefisien korelasi $(r)=0,150$ yang berarti bahwa ada hubungan positif lemah dengan nilai kemaknaan yang rendah antara gambaran Foto Waters dan gejala klinik pada penderita dengan dugaan sinusitis maksilaris.
\end{abstract}

Kata kunci: Sinusitis maksilaris, Gejala klinik, Foto Waters. 
Sinusitis adalah inflamasi mukosa sinus paranasal yang merupakan penyakit yang sering ditemukan dalam praktek dokter sehari hari, bahkan dianggap sebagai salah satu penyebab gangguan kesehatan tersering diseluruh dunia. Menurut Gluckman, kuman penyebab sinusitis akut tersering adalah streptococcus pneumonia dan haemophilus infuenzae yang ditemukan pada 70\% kasus. Insiden sinusitis yang paling sering di temukan ialah sinusitis maksilaris dan sinusitis etmoidalis. Di Bagian Radiologi BLU RSUP Prof. Dr. R. D. Kandou Manado menunjukan angka kejadian sinusitis maksilaris yang cukup tinggi yaitu 60 orang penderita $(61,86 \%)$ dari 97 orang penderita yang melakukan pemeriksaan Foto Waters pada tahun 2011. Kriteria diagnosis sinusitis maksilaris berupa adanya gejala klinik mayor seperti pilek, hidung buntu, rasa nyeri pada wajah atau pipi, rasa berat pada wajah, anosmia serta panas badan; dan gejala klinik minor seperti sakit kepala, hidung bau, rasa lelah, batuk serta nyeri atau penuh pada telinga. Diagnosis sinusitis ditegakkan bila didapatkan 1 atau 2 gejala klinik mayor dan 2 gejala klinik minor. Ada berbagai pemeriksaan klinik yang dapat dilakukan untuk mencurigai adanya sinusitis maksilaris seperti anamnesis, pemeriksaan fisik dan pemeriksaan penujang. Untuk mengetahui diagnosis secara pasti dan memberikan diagnosis yang lebih dini, maka diperlukan pemeriksaan radiologis. Adapun pemeriksaan yang sering digunakan ialah Foto Waters, CT Scan dan MRI. Pemeriksaan Foto Waters adalah pemeriksaan yang paling sering digunakan untuk mengevaluasi infeksi sinus paranasal. Foto Waters umumnya dilakukan pada keadaan mulut terbuka. Dengan pemeriksaan Foto Waters, CT scan dan MRI dapat melihat adanya perselubungan, penebalan mukosa atau

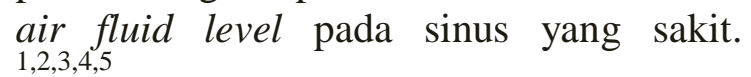

Berdasarkan latar belakang di atas dan banyaknya penderita dengan gejala klinik sinusitis maksilaris serta permintaan Foto Waters di Bagian Radiologi BLU RSUP Prof. Dr. R. D. Kandou Manado, maka penulis terdorong untuk melakukan penelitian, sebab penelitian mengenai hubungan antara Foto Waters dan gejala klinik pada penderita dengan dugaan sinusitis maksilaris belum pernah dilakukan. Selain itu penelitian ini dapat mengetahui apakah ada hubungan antara Foto Waters dan gejala klinik pada penderita dengan dugaan sinusitis maksilaris di RSUP Prof. DR. R. D. Kandou Manado periode 1 Oktober 2012 30 September 2013.

Penelitian ini tujuannya untuk mengetahui apakah ada hubungan antara gambaran Foto Waters dan gejala klinik pada penderita dengan dugaan sinusitis maksilaris di RSUP Prof. Dr. R. D. Kandou Manado periode 1 Oktober 201230 September 2013 dan bagaimana persentase penderita sinusitis maksilaris di RSUP Prof. Dr. R. D. Kandou Manado periode 1 Oktober 2012-30 September 2013?

\section{METODE PENELITIAN}

Penelitian ini adalah penelitian analitik korelatik retrospektif dengan memanfaatkan data sekunder berupa lembaran gejala klinik sinusitis maksilaris dan hasil gambaran Foto Waters di RSUP Prof DR. R. D. Kandou Manado dan diolah dalam bentuk deskriptif dan analitik. Waktu penelitian berlangsung November 2013-Januari 2014 dan sampelnya yaitu Semua lembaran permintaan gambaran Foto Waters dan gejala klinik pada penderita dengan dugaan sinusitis maksilaris di RSUP Prof. Dr. R. D. Kandou Manado periode 1 Oktober 201230 September 2013.

\section{HASIL DAN PEMBAHASAN}

Selama periode 1 Oktober 2012-30 September 2013 ditemukan penderita dengan gejala klinik sinusitis maksilaris 
yang melakukan pemeriksaan Foto Waters di RSUP Prof Dr. R. D. Kandou Manado berjumlah 45 orang.

Tabel 1. Distribusi diagnosis radiologi penderita dengan dugaan sinusitis maksilaris.

\begin{tabular}{ccc}
\hline Diagnosis radiologi & n & \% \\
\hline Sinusitis maksilaris & 24 & 53,34 \\
Tak ada kelainan & 21 & 46,66 \\
\hline Jumlah & $\mathbf{4 5}$ & $\mathbf{1 0 0}$ \\
\hline
\end{tabular}

Dari tabel 1. ditemukan penderita dengan gejala klinik sinusitis maksilaris yang melakukan pemeriksaan Foto Waters di RSUP Prof Dr. R. D. Kandou Manado berjumlah 24 orang penderita (53,34\%) dengan diagnosis sinusitis maksilaris dan 21 orang penderita (46,66\%) tidak ada kelainan. Seperti yang ditemukan Posumah (2013) di RSUP Prof. DR. R. D. Kandou Manado, didapatkan sebanyak 60 orang penderita $(61,81 \%)$ dengan diagnosis sinusitis maksilaris dan tidak ada kelainan sebanyak 37 orang penderita (38,14\%). Arivalagan et al (2013), dalam penelitiannya menunjukan sinus yang paling sering terinfeksi adalah sinus maksilaris dengan bilangan sebanyak 144 orang penderita $(54,6 \%)$.

Sinus maksilaris merupakan sinus paranasal terbesar dan yang paling sering terkena infeksi karena ostium sinus maksilaris terletak lebih tinggi dari dasar sinus, sehingga drainase hanya tergantung dari gerak silia, drainase juga terjadi melalui infundibulum yang sempit. ${ }^{7}$

Tabel 2. Distribusi jenis kelamin penderita dengan dugaan sinusitis maksilaris.

\begin{tabular}{ccc}
\hline Jenis kelamin & n & \% \\
\hline Laki-laki & 21 & 46,66 \\
Perempuan & 24 & 53,34 \\
\hline Jumlah & $\mathbf{4 5}$ & $\mathbf{1 0 0}$ \\
\hline
\end{tabular}

Dari tabel 2. ditemukan penderita dengan gejala klinik sinusitis maksilaris yang melakukan pemeriksaan Foto Waters di RSUP Prof Dr. R. D. Kandou Manado berjumlah 21 orang (46,66\%) pada penderita laki-laki dan 24 orang (53,34\%) pada penderita perempuan. Hasil yang didapatkan penelitian ini tidak jauh berbeda dengan peneliti-peneliti sebelumnya, seperti yang didapatkan oleh Tandiyo et al (2012) mendapatkan jumlah sampel terdiri dari 6 laki-laki (42,9\%) dan 8 perempuan $(57,1 \%)$. Hal ini berbeda dengan yang didapatkan oleh Elfahmi (2001) dan Septiwati et al (2013), mereka mendapatkan penderita laki-laki lebih banyak dari pada perempuan. ${ }^{4,6,7,8}$

Tabel 3. Distribusi umur penderita dengan dugaan sinusitis maksilaris.

\begin{tabular}{ccc}
\hline Umur & $\mathbf{n}$ & $\mathbf{\%}$ \\
\hline $18-33$ & 10 & 22,22 \\
$34-48$ & 15 & 33,33 \\
$48-63$ & 14 & 31,11 \\
$64-75$ & 6 & 13,34 \\
\hline Jumlah & $\mathbf{4 5}$ & $\mathbf{1 0 0}$ \\
\hline
\end{tabular}

Dari tabel 3. ditemukan penderita dengan gejala klinik sinusitis maksilaris yang melakukan pemeriksaan Foto Waters di RSUP Prof Dr. R. D. Kandou Manado berjumlah 10 orang penderita (22,22\%) pada kelompok umur 18-33, 15 orang penderita (33,33\%) pada kelompok umur 34-48, 14 orang penderita $(31,11 \%)$ pada kelompok umur 48-63 dan 6 orang penderita $(13,34 \%)$ pada kelompok umur 64-75. Pada penelitian yang dilakukan oleh Septiwati (2013), ditemukan kelompok umur tertinggi yaitu umur 31-40 tahun berjumlah 8 orang penderita (23,5\%) dan pada kelompok umur terendah yaitu umur 61-70 tahun dan 71-80 tahun berjumlah 1 orang penderita (2,9\%). Arivalagan (2013) mendapatkan kelompok umur terbanyak yaitu pada kelompok umur 30-45 tahun berjumlah 60 orang penderita (31,6 \%) 
diikutioleh kelompok umur 46-60 tahun berjumlah 59 orang penderita (31,1\%). Jumlah penderita yang paling sedikit dijumpai pada pada kelompok usia 0-15 tahun yaitu berjumlah 8 orang penderita $(4,2 \%)$. Dari data di atas terlihat umur yang paling banyak hampir sama, yaitu pada usia dewasa. Posumah di RSUP Prof. Dr. R. D. Kandou Manado (2013) menyimpulkan apa yang dinyatakan oleh Dalimunthe (2010), bahwa hal tersebut disebabkan kelompok usia dewasa merupakan kelompok usia yang aktif dan sering terpapar oleh polutan atau zat-zat iritasi yang mungkin dapat menyebabkan atau memperberat terjadinya sinusitis maksilaris sehingga menyebabkan penderita lebih banyak pada kelompok usia dewasa yang datang berobat ke rumah sakit. ${ }^{3,6,7}$

Tabel 4. Distribusi gambaran Foto Waters penderita dengan dugaan sinusitis maksilaris.

\begin{tabular}{ccc}
\hline Gambaran foto waters & $\mathbf{n}$ & $\mathbf{\%}$ \\
\hline Penebalan mukosa & 7 & 15,56 \\
Perselubungan & 15 & 33,33 \\
Air fluid level & 2 & 4,44 \\
Tidak ada kelainan & 21 & 46,67 \\
\hline Jumlah & $\mathbf{4 5}$ & $\mathbf{1 0 0}$ \\
\hline
\end{tabular}

Dari tabel 4. ditemukan penderita dengan gejala klinik sinusitis maksilaris yang melakukan pemeriksaan Foto Waters di RSUP Prof Dr. R. D. Kandou Manado berjumlah 7 orang penderita (15,56\%) dengan penebalan mukosa, 15 orang penderita (33,33\%) dengan perselubungan, 2 orang penderita $(4,44 \%)$ dengan air fluid level dan 21 orang penderita (46,67\%) tidak ada kelainan sinusitis maksilaris. Sama halnya dengan Yoshiura et al (Jepang, 1993) peneliti sinusitis maksilaris dan Suzanne et al (New york, 2001) menyatakan gambaran radiologi yang terbanyak adalah perselubungan. Posumah (2013) mendapatkan gambaran Foto waters terbanyak yaitu dengan gambaran perselubungan dengan jumlah 43 orang penderita (76, 67\%), dan tidak ditemukan gambaran air fluid level pada penderita sinusitis maksilaris. Hasil dari peneliti peneliti sebelumnya memiliki gambaran yang hampir sama, dimana gambaran Foto Waters pada penderita sinusitis maksilaris paling sering ditemukan pada gambaran perselubungan dan yang terendah ditemukan pada gambaran air fluid level. $^{3,8}$

Tabel 5. Distribusi penderita gejala klinik penderita dengan dugaan sinusitis maksilaris.

\begin{tabular}{ccc}
\hline Gejala klinik & n & \% \\
\hline 1 gejala klinik & 22 & 48,9 \\
2 gejala klinik & 19 & 42,22 \\
3 gejala klinik & 2 & 4,44 \\
4 gejala klinik & 2 & 4,44 \\
\hline jumlah & $\mathbf{4 5}$ & $\mathbf{1 0 0}$ \\
\hline
\end{tabular}

Dari tabel 5. Di temukan penderita dengan gejala klinik sinusitis maksilaris yang melakukan pemeriksaan Foto Waters di RSUP Prof Dr. R. D. Kandou Manado berjumlah 22 orang penderita (48,8\%) dengan 1 gejala klinik sinusitis maksilaris, 19 orang penderita (42,22\%) dengan 2 gejala klinik sinusitis maksilaris, 2 orang penderita $(4,44 \%)$ dengan 3 gejala klinik sinusitis maksilaris dan 2 orang penderita (4,44\%) dengan 4 gejala klinik sinusitis maksilaris.

Tabel 7. Distribusi korelasi hubungan antara Foto Waters dengan skoring gejala klinik pada penderita dengan dugaan sinusitis maksilaris.

\begin{tabular}{ccccc}
\multicolumn{5}{c}{ Correlations } \\
\hline & & & $\begin{array}{c}\text { Foto } \\
\text { Waters }\end{array}$ & $\begin{array}{c}\text { Skoring } \\
\text { gejala } \\
\text { klinik }\end{array}$ \\
\hline & Foto & $\mathrm{r}$ & 1,000 &, 150 \\
Kendall's & & $\mathrm{n}$ & 45 & 45 \\
tau_b & & & & \\
& $\begin{array}{c}\text { Skoring } \\
\text { gejala }\end{array}$ & $\mathrm{r}$ &, 150 & 1,000 \\
& klinik & $p$ &, 272 & \\
& & $\mathrm{n}$ & 45 & 45 \\
\hline
\end{tabular}


Berdasarkan uji korelasi Kendall'tau_b nilai signifikan $(p)=0,272$ $>0,05$ dan koefisien korelasi $(r)=0,150$ yang berarti bahwa ada hubungan positif lemah dengan nilai kemaknaanm yang rendah antara gambaran Foto Waters dan skoring gejala klinik pada penderita dengan dugaan sinusitis maksilaris.

Tabel 8. Distribusi korelasi hubungan antara Foto Waters dan gejala klinik nyeri kepala/wajah pada penderita dengan dugaan sinusitis maksilaris.

\begin{tabular}{|c|c|c|c|c|}
\hline \multicolumn{5}{|c|}{ Correlations } \\
\hline & & & $\begin{array}{c}\text { Foto } \\
\text { Waters }\end{array}$ & $\begin{array}{c}\text { Nyeri } \\
\text { Kepala/ } \\
\text { Wajah }\end{array}$ \\
\hline \multirow{6}{*}{$\begin{array}{l}\text { Kendall's } \\
\text { tau_b }\end{array}$} & Foto & $\mathrm{r}$ & 1,000 & -,004 \\
\hline & Waters & $p$ & & ,980 \\
\hline & \multirow{4}{*}{$\begin{array}{c}\text { Nyeri } \\
\text { Kepala/ } \\
\text { Wajah }\end{array}$} & $\mathrm{n}$ & 45 & 45 \\
\hline & & $r$ &,- 004 & 1,000 \\
\hline & & $p$ & 980 & \\
\hline & & $\mathrm{n}$ & 45 & 45 \\
\hline
\end{tabular}

Berdasarkan uji korelasi Kendall'tau_b nilai signifikan $(p)=0,980>$ 0,05 dan koefisien korelasi $(r)=-0,004$ berarti bahwa ada hubungan negatif yang lemah dengan nilai kemaknaan yang sangat rendah antara gambaran Foto Waters dan gejala klinik nyeri kepala/wajah pada penderita dengan dugaan sinusitis maksilaris.
Tabel 9. Distribusi korelasi hubungan antara Foto Waters dan gejala klinik pilek pada penderita dengan dugaan sinusitis maksilaris

Correlations

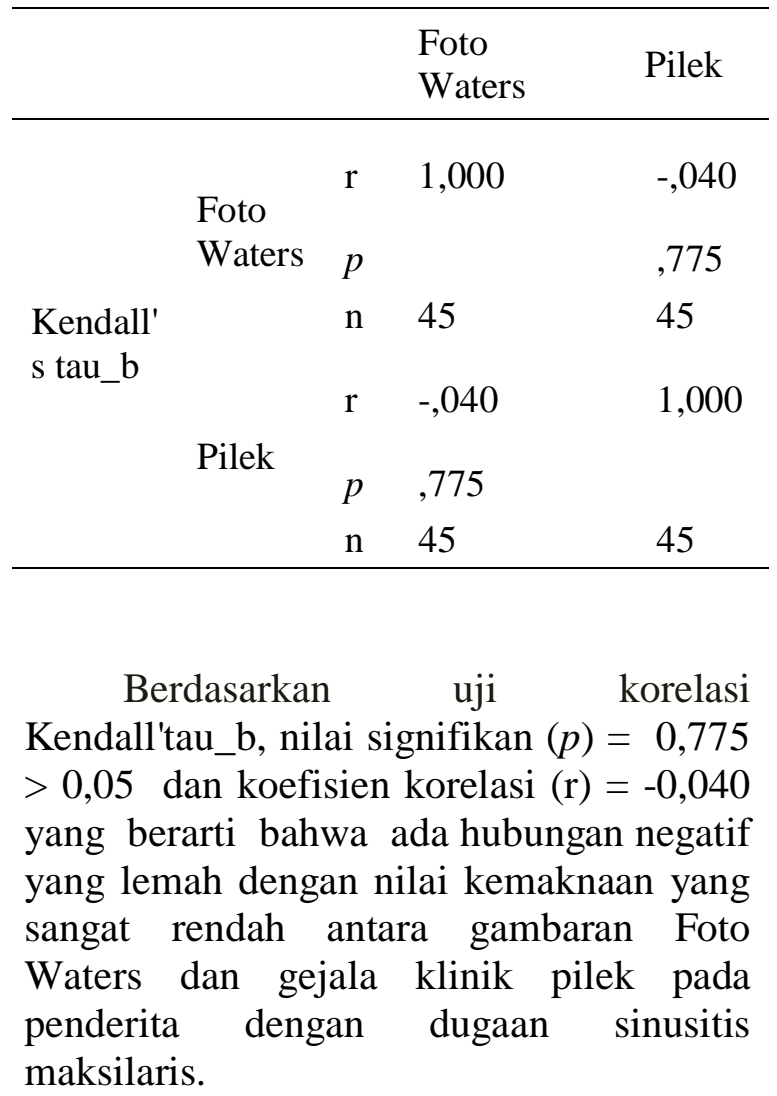

Tabel 10. Distribusi korelasi hubungan antara Foto Waters dan hidung buntu pada penderita dengan dugaan sinusitis maksilaris.

\section{Correlations}

\begin{tabular}{ccccc}
\hline & & & $\begin{array}{c}\text { Foto } \\
\text { Waters }\end{array}$ & $\begin{array}{c}\text { Hidung } \\
\text { Buntu }\end{array}$ \\
\hline & & $\mathrm{r}$ & 1,000 &, 111 \\
& Foto & & &, 435 \\
Waters & $p$ & & 45 \\
Kendall' & & $\mathrm{n}$ & 45 & \\
& & $\mathrm{r}$ &, 111 & 1,000 \\
& Hidung & & & \\
& Buntu & $p$ &, 435 & \\
& & $n$ & 45 & 45 \\
\hline
\end{tabular}


Berdasarkan uji korelasi Kendall'tau_b, nilai signifikan $(p)=0,435$ $>0,05$ dan koefisien korelasi $(r)=0,111$ yang berarti bahwa ada hubungan positif lemah dengan nilai kemaknaan yang rendah antara gambaran Foto Waters dan gejala klinik hidung buntu pada penderita dengan dugaan sinusitis maksilaris.

Tabel 11. Distribusi korelasi hubungan antara Foto Waters dan keluar sekret dari hidung pada penderita dengan dugaan sinusitis maksilaris.

\begin{tabular}{lllll}
\multicolumn{4}{c}{ Correlations } \\
& & & $\begin{array}{l}\text { Foto } \\
\text { Waters }\end{array}$ & $\begin{array}{l}\text { Sekret } \\
\text { Dari } \\
\text { Hidung }\end{array}$ \\
\hline & & $\mathrm{r}$ & 1,000 &, 224 \\
& Foto & & &, 114 \\
& Waters & $p$ & & 45 \\
$\begin{array}{l}\text { Kendall's } \\
\text { tau_b }\end{array}$ & & $\mathrm{n}$ & 45 & 45 \\
& Sekret & $\mathrm{r}$ &, 224 & 1,000 \\
& Dari & & & \\
& Hidung & $p$ &, 114 & \\
& & $n$ & 45 & 45 \\
\hline
\end{tabular}

Berdasarkan uji korelasi Kendall'tau_b, nilai $p=0,114>0,05$, dan koefisien korelasi $(r)=0,22$ yang berarti bahwa ada hubungan positif lemah dengan nilai kemaknaan yang rendah antara gambaran Foto Waters dan keluar sekret dari hidung pada penderita dengan dugaan sinusitis maksilaris.

\section{SIMPULAN}

Berdasarkan hasil penelitian yang dilakukan di RSUP Prof. Dr. R. D. Kandou Manado periode 1 Oktober 2012-30 September 2013 dapat disimpulkan bahwa dari hasil uji korelasi antara gambaran Foto Waters dan gejala klinik pada penderita dengan dugaan sinusitis maksilaris didapatkan ada hubungan positif lemah dengan nilai kemaknaan yang rendah antara gambaran Foto Waters dan gejala klinik pada penderita dengan dugaan sinusitis maksilaris.

\section{SARAN}

Dianjurkan pada penderita dengan gejala klinik sinusitis maksilaris untuk melakukan pemeriksaan Foto Waters dan Kepada BPJS agar dapat membiayai pemeriksaan Foto Waters dimana pemeriksaan ini sangat disarankan untuk penderita dengan dugaan sinusitis maksilaris, karena mendiagnosis berdasarkan gejala klinik dan dengan melakukan pemeriksaan Foto Waters hasil diagnosisnya dapat berbeda.

\section{UCAPAN TERIMA KASIH}

Penulis mengucapkan terima kasih kepada dr Olivia C. Pelealu, Sp.THT-KL dan DR. dr. Erwin Kristanto, SH, Sp.F selaku penguji 1 dan penguji 2 atas masukan dan saran, serta kepada pihakpihan yang secara langsung atau tidak langsung telah memberikan gagasan dan ide kepada penulis.

\section{DAFTAR PUSTAKA}

1. Soetjipto D, Mangunkusumo E. Sinus Paranasal.Dalam: Soepardi EA, Iskandar $\mathrm{N}$, Bashiruddin J, Restuti RD, editor. Buku ajar ilmu kesehatan telinga hidung tenggorok kepala dan leher. Edisi ke-6. Jakarta : FK UI, 2007; p. 145-53.

2. Sinusitis. Dalam: Mansjoer A, Triyanti K, savitri R, Wardhani W, Setiowulan W, editor. Kapita selekta kedokteran, Jilid 1. Edisi ke-3. Media Aesculaplus FKUI. Jakarta. 2001; hal 102-6.

3. Posuma AH. Gambaran Foto Waters pada penderita dengan dugaan sinusitis maksilaris di RSUP Prof Dr. R. D. Kandou Manado. Jurnal e-Biomedik (eMB). 2013;1:129-34.

4. Tandiyo DK, Rochman F, Maria P, Surarso B, Kristyono I. Perbedaan hasil terapi low level laser therapy dosos 2 $\mathrm{J} / \mathrm{cm}^{2}$ dan $4 \mathrm{~J} / \mathrm{cm}^{2}$ pada penderita sinusitis maksilaris akut rinogen. CDK. 2012;39:656-8.

5. Ranchman MD. Sinus paranasal. Dalam: Rasad. S. Radiologi diagnostic. Edisi ke2. Jakarta : FKUI; 2005. p. 431-8. 
6. Arivanlagan P, Rambe A. Gambaran rinosinusitis kronik di RSUP Haji Malik Tahun 2011. E-Jurnal FK-USU. 2013;1:1.

7. Septiwati M, Taher A, Rahayu U. Hubungan infeksi gigi rahang atas dengan kejadian rhinosinusitis maksilaris di RSUD Raden Matteaher Jambi. The jambi medical journal. 2013;1:1.
8. Farhat. Peran infeksi gigi rahang atas pada kejadian sinusitis maksilaris di RSUP H. Adam Malik Medan. Majalah kedokteran nusantara. 2006;39:386-92. 